\title{
ARM
}

CLIMATE RESEARCH FACILITY

\section{G-Band Vapor Radiometer Profiler (GVRP) HANDBOOK}

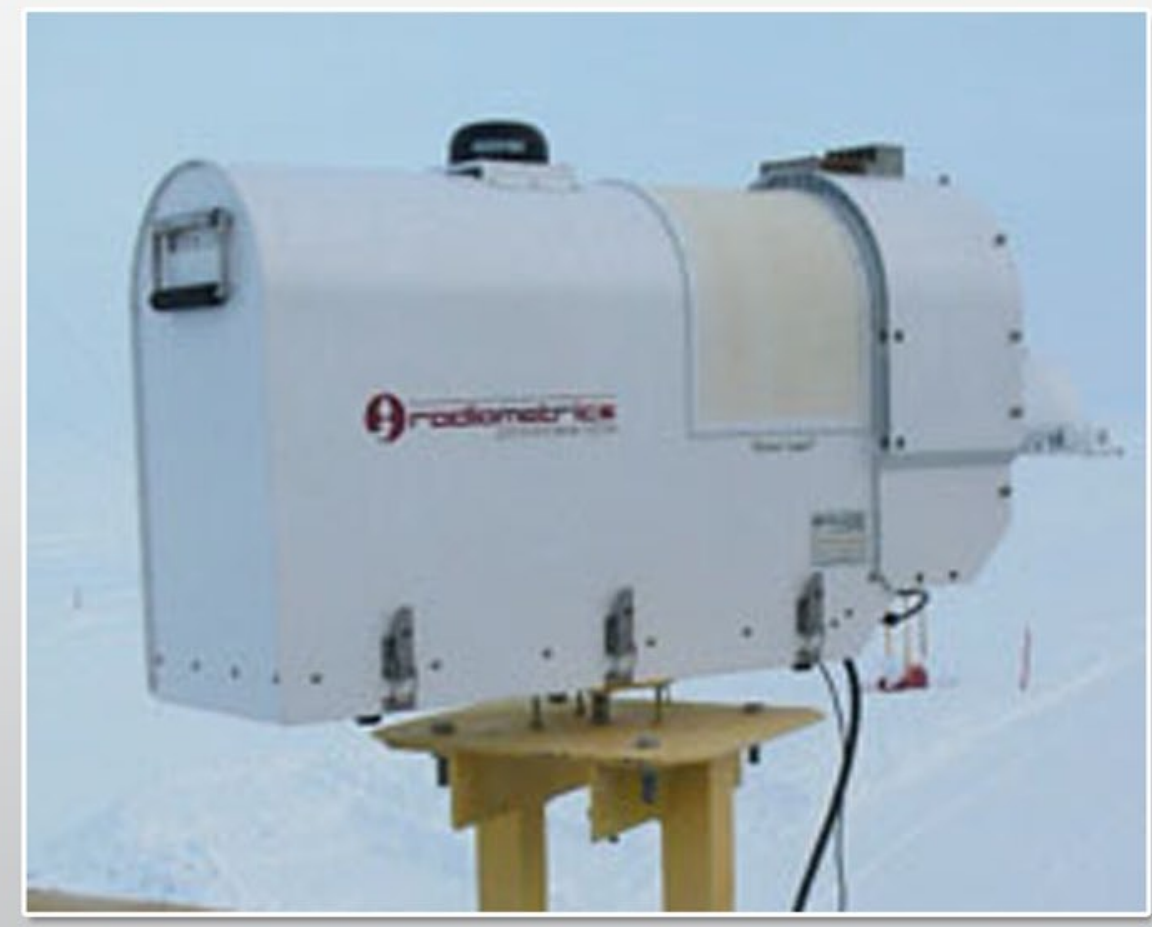

June 2010 


\section{DISCLAIMER}

This report was prepared as an account of work sponsored by the U.S. Government. Neither the United States nor any agency thereof, nor any of their employees, makes any warranty, express or implied, or assumes any legal liability or responsibility for the accuracy, completeness, or usefulness of any information, apparatus, product, or process disclosed, or represents that its use would not infringe privately owned rights. Reference herein to any specific commercial product, process, or service by trade name, trademark, manufacturer, or otherwise, does not necessarily constitute or imply its endorsement, recommendation, or favoring by the U.S. Government or any agency thereof. The views and opinions of authors expressed herein do not necessarily state or reflect those of the U.S. Government or any agency thereof. 


\section{G-Band Vapor Radiometer Profiler (GVRP) Handbook}

MP Cadeddu

Argonne National Laboratory

June 2010

Work supported by the U.S. Department of Energy,

Office of Science, Office of Biological and Environmental Research 


\section{Contents}

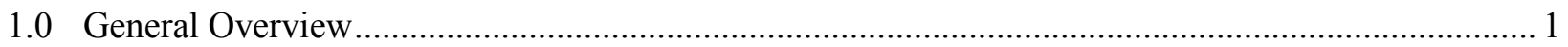

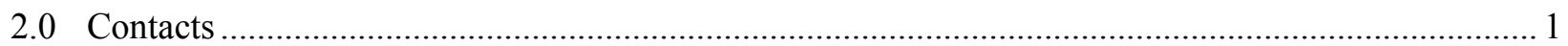

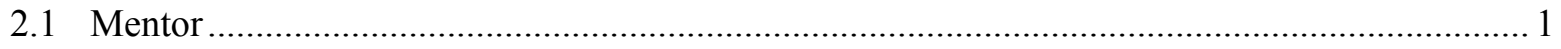

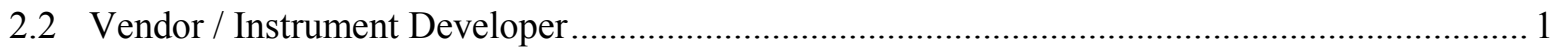

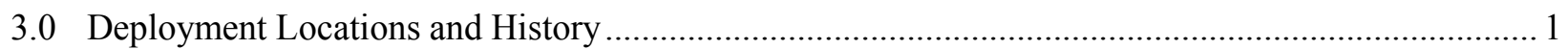

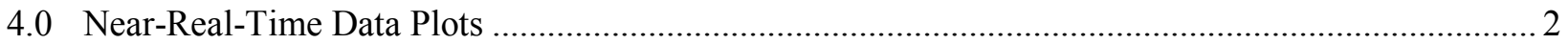

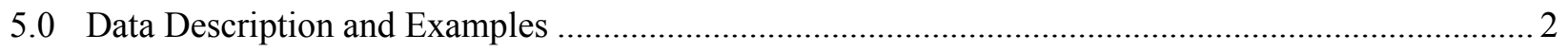

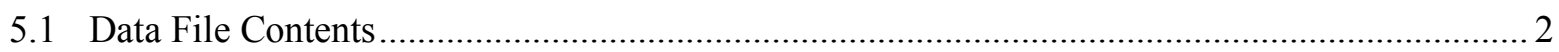

5.1.1 Primary Variables and Expected Uncertainty ........................................................... 2

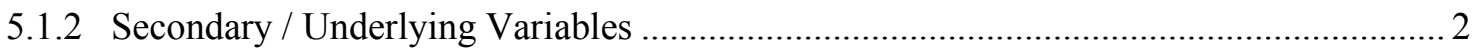

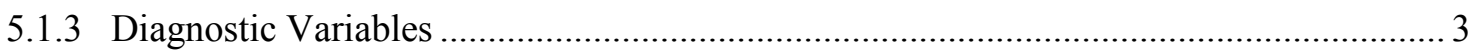

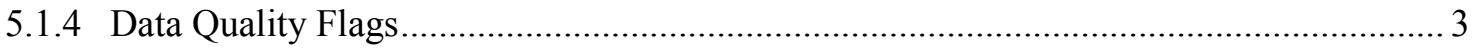

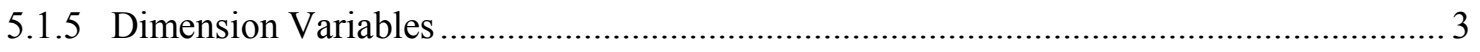

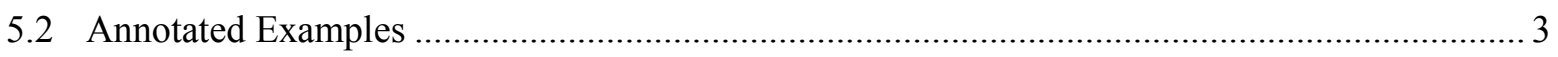

5.3 User Notes and Known Problems …..................................................................................... 3

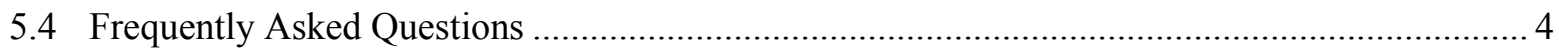

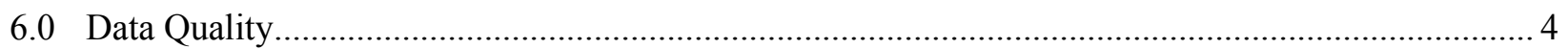

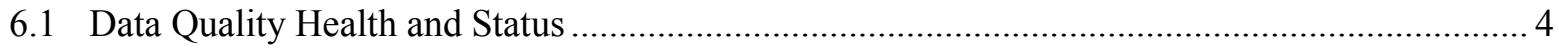

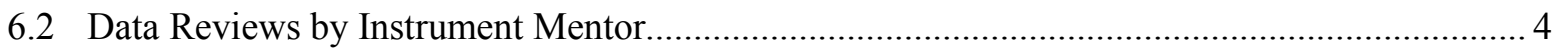

6.3 Data Assessments by Site Scientist / Data Quality Office ..................................................... 4

6.4 Value-Added Products and Quality Measurement Experiments................................................ 4

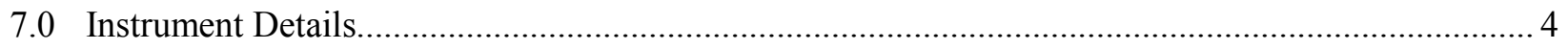

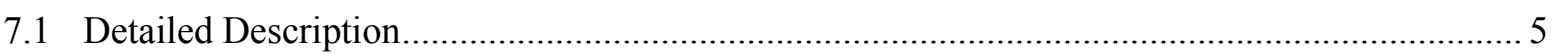

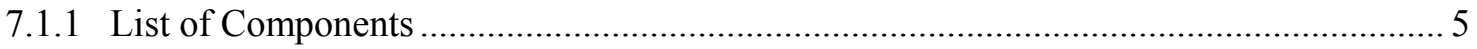

7.1.2 System Configuration and Measurement Methods .................................................... 5

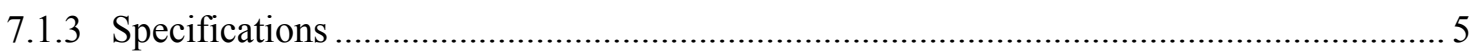

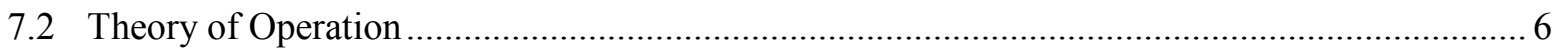

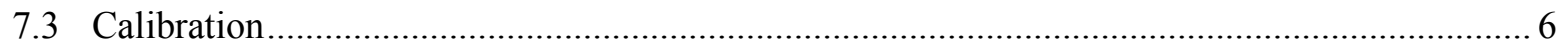

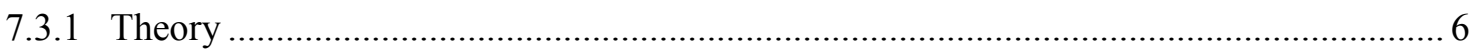

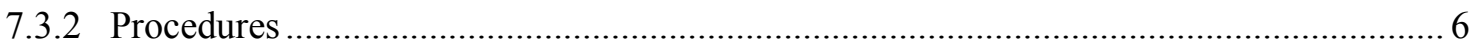

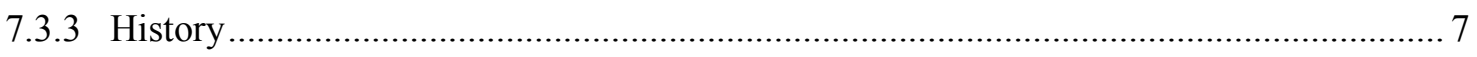

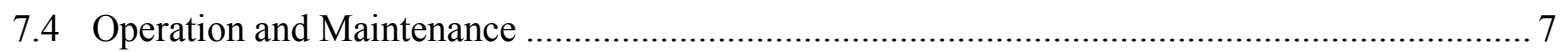

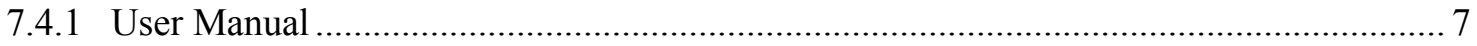

7.4.2 Routine and Corrective Maintenance Documentation ................................................. 7

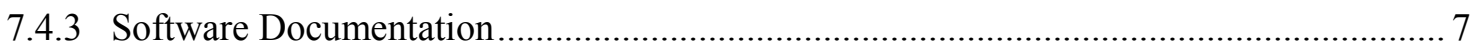




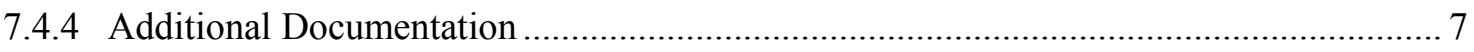

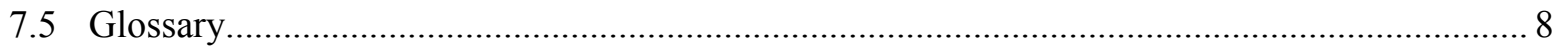

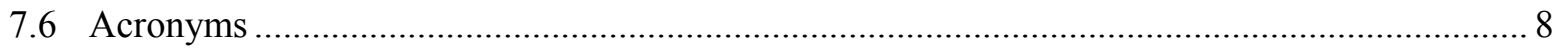

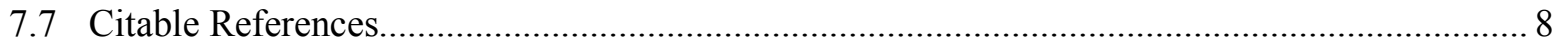

\section{Tables}

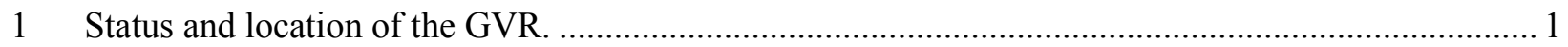

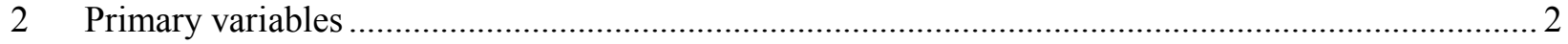

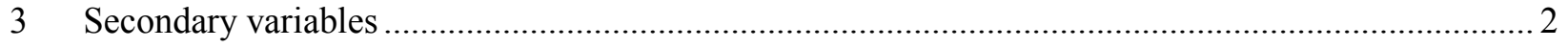

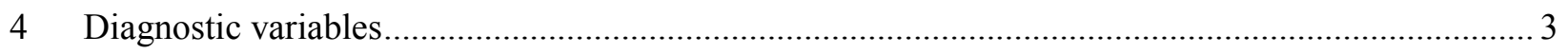

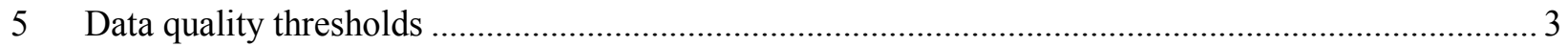

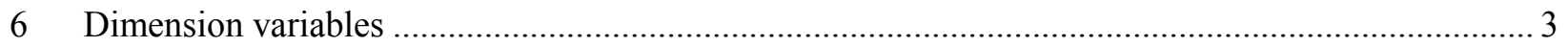

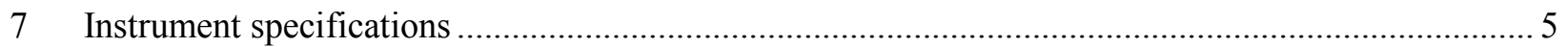




\subsection{General Overview}

The G-Band Vapor Radiometer Profiler (GVRP) provides time-series measurements of brightness temperatures from 15 channels between 170 and $183.310 \mathrm{GHz}$. Atmospheric emission in this spectral region is primarily due to water vapor, with some influence from liquid water. Channels between 170.0 and $176.0 \mathrm{GHz}$ are particularly sensitive to the presence of liquid water. The sensitivity to water vapor of the $183.31-\mathrm{GHz}$ line is approximately 30 times higher than at the frequencies of the two-channel microwave radiometer (MWR) for a precipitable water vapor (PWV) amount of less than $2.5 \mathrm{~mm}$. Measurements from the GVRP instrument are therefore especially useful during low-humidity conditions (PWV $<5 \mathrm{~mm}$ ). In addition to integrated water vapor and liquid water, the GVRP can provide lowresolution vertical profiles of water vapor in very dry conditions.

\subsection{Contacts}

\subsection{Mentor}

Maria Cadeddu

Decision and Information Sciences Division

Argonne National Laboratory, Bldg. 900

Argonne, Illinois 60439

630.252.7408

mcadeddu@anl.gov

\subsection{Vendor / Instrument Developer}

Radiometrics Corporation.

2840 Wilderness Place Unit G

Boulder, CO 80301-5414

303.449 .9192

info@radiometrics.com

\subsection{Deployment Locations and History}

Table 1. Status and location of the GVRP.

\begin{tabular}{|c|c|l|l|l|c|}
\hline Serial Number & $\begin{array}{c}\text { Property } \\
\text { Number }\end{array}$ & \multicolumn{1}{|c|}{ Location } & Date Installed & Date Removed & Status \\
\hline MP3000A 183-2 & & NSA/C1 & $2008 / 03 / 31$ & & Operational \\
\hline
\end{tabular}




\subsection{Near-Real-Time Data Plots}

Plots of near-real-time data can be viewed at the DQHands (Data Quality Health and Status) system accessible through the web site: http://dq.arm.gov/. Click on "QC Metrics and Plots" and select the desired site and data stream. The GVRP is located at the site "NSA", the datastream is "nsagvrpC1.b1" or "nsagvrpC1.a1", and the facility is "C1".

\subsection{Data Description and Examples}

\subsection{Data File Contents}

Datastreams available from the ARM Data Archive are:

- nsagvrpC1.a1: Raw data

- nsagvrpC1.b1: Calibrated, brightness temperatures and surface ambient measurements.

\subsubsection{Primary Variables and Expected Uncertainty ${ }^{1}$}

The primary variables measured by the GVRP are brightness temperatures at 15 channels between 170 and $183.3 \mathrm{GHz}$.

Table 2. Primary variables.

\begin{tabular}{|l|l|l|l|}
\hline \multicolumn{1}{|c|}{ Variable Name } & \multicolumn{1}{|c|}{ Quantity Measured } & \multicolumn{1}{c|}{ Unit } & Uncertainty \\
\hline Brightness temperature & Sky brightness temperature $(15$ channels $)$ & $\mathrm{K}$ & $2 \mathrm{~K}$ \\
\hline Frequency & $\begin{array}{l}170.0,171.0,172.0,173.0,174.0,175.0,176.0, \\
177.0,178.0,179.0,180.0,181.0,182.0,183.0, \\
\text { and } 183.310\end{array}$ & $\mathrm{GHz}$ & N/A \\
\hline Elevation & Elevation viewing angles $(90=$ zenith viewing) & Degrees & N/A \\
\hline
\end{tabular}

\subsubsection{Secondary / Underlying Variables}

Table 3. Secondary variables.

\begin{tabular}{|l|l|l|l|}
\hline \multicolumn{1}{|c|}{ Variable Name } & \multicolumn{1}{c|}{ Quantity Measured } & \multicolumn{1}{c|}{ Unit } & \multicolumn{1}{c|}{ Uncertainty } \\
\hline time & Time offset from midnight & $\mathrm{s}$ & \\
\hline surfacePressure & Pressure at the surface & $\mathrm{kPa}$ & 2.0 \\
\hline surfaceTemperature & Temperature at the surface & $\mathrm{K}$ & 1.0 \\
\hline surfaceRelativeHumidity & Relative humidity at the surface & $\%$ & 5.0 \\
\hline surfaceRainFlag & Binary rain indicator $(1=$ rain, $0=$ no-rain $)$ & count & N/A \\
\hline
\end{tabular}

\footnotetext{
${ }^{1}$ See section (6.5) for a definition of uncertainty.
} 


\subsubsection{Diagnostic Variables}

Table 4. Diagnostic variables.

\begin{tabular}{|l|l|l|l|}
\hline \multicolumn{1}{|c|}{ Variable Name } & \multicolumn{1}{|c|}{ Quantity Measured } & \multicolumn{1}{c|}{ Unit } & \multicolumn{1}{c|}{ Uncertainty } \\
\hline blackBodyTemperature & Internal blackbody reference temperature & $\mathrm{K}$ & $0.25 \mathrm{~K}$ \\
\hline noiseDiodePhysicalTemp & Noise diode physical temperature & $\mathrm{K}$ & $0.25 \mathrm{~K}$ \\
\hline
\end{tabular}

\subsubsection{Data Quality Flags}

Data quality flags are named qc_'fieldname' (i.e., qc_surfacePressure). Possible values for qc_flags are: 0 (value is within the specified range), 1 (missing value), 2 (value is less than the specified minimum), 4 (value is greater than the specified maximum), and 8 (value failed the valid "delta" check). Specified maximum and minimum values are shown in Table 5.

Table 5. Data quality thresholds.

\begin{tabular}{|l|l|l|}
\hline \multicolumn{1}{|c|}{ Field Name } & \multicolumn{1}{c|}{ Min } & \multicolumn{1}{c|}{ Max } \\
\hline BrightnessTemperature & 3 & 320 \\
\hline surfacePressure & 80 & 110 \\
\hline surfaceTemperature & 223.15 & 323 \\
\hline surfaceRelativeHumidity & 1 & 110 \\
\hline blackBodyTemperature & 243 & 320 \\
\hline
\end{tabular}

\subsubsection{Dimension Variables}

Table 6. Dimension variables.

\begin{tabular}{|l|l|l|}
\hline \multicolumn{1}{|c|}{ Field Name } & \multicolumn{1}{c|}{ Quantity } & \multicolumn{1}{c|}{ Unit } \\
\hline base_time & Base time in Epoch & seconds since 1970-1-1 0:00:00 0:00 \\
\hline time_offset & Time offset from base_time & s \\
\hline lat & north latitude & degrees \\
\hline lon & east longitude & degrees \\
\hline alt & altitude & meters above Mean Sea Level \\
\hline
\end{tabular}

\subsection{Annotated Examples}

This section is not yet available.

\subsection{User Notes and Known Problems}

The instrument is calibrated with LN2 calibration every 3-4 months. Information on calibration is available in the calibration database and upon request to the instrument mentor. 


\subsection{Frequently Asked Questions}

This section is not yet available.

\subsection{Data Quality}

\subsection{Data Quality Health and Status}

Daily quality check on this data stream can be found at the DQHands web page: http://dq.arm.gov/. Click on "QC Metrics and Plots" and select the desired site and datastream. The GVRP is located at the site "NSA", the data stream is "nsagvrpC1.b1" or "nsagvrpC1.a1", and the facility is "C1".

\subsection{Data Reviews by Instrument Mentor}

The instrument mentor submits a monthly summary report IMMS accessible from the instrument web page. Some of the general checks performed by the instrument mentor are shown below.

1. In general the brightness temperature time series should be smooth and with low noise levels.

2. Brightness temperatures should be greater than $2.75 \mathrm{~K}$ and less than approximately $310 \mathrm{~K}$. (We do not expect the ambient temperature in Barrow to be significantly higher than $30^{\circ} \mathrm{C}$ ).

3. Surface meteorological readings (temperature, pressure, and relative humidity) can be compared to tower measurements. The agreement should be $+/-2 \mathrm{~K}$ for temperature, about $5 \mathrm{kPa}$ for pressure, and $5 \%$ for relative humidity.

4. Measured brightness temperatures are also compared routinely with model computations as a general quality check.

\subsection{Data Assessments by Site Scientist / Data Quality Office}

The Data Quality office daily data assessment can be viewed at the DQHands web page: http://dq.arm.gov/.

\subsection{Value-Added Products and Quality Measurement Experiments}

No value-added products are available at this stage.

\subsection{Instrument Details}

The GVRP is part of a new series of microwave radiometers (Radiometrics MP-3000A series) with advanced frequency agile architecture and user interface. 


\subsection{Detailed Description}

\subsubsection{List of Components}

- RF section: Mailbox-type container

- Desktop PC host computer with monitor, keyboard, and mouse

- Super-blower

- Calibration target and saddle

- Data and power cables.

\subsubsection{System Configuration and Measurement Methods}

In this section we give a brief description of the GVRP hardware configuration. The material in this section can be found in [1]. The reference can be obtained from the instrument mentor upon request. The downwelling atmospheric radiation passes through the instrument radome. A parabolic mirror reflects the radiation into the receiver feed-horn. Microwave channels are selected using a frequency synthesizer. Input power is down-converted to an intermediate frequency. The signal is then amplified, filtered, and detected. The receiver has a noise source (noise diode) used to calibrate the gain. The instrument is equipped with elevation-scanning capability. Eleven elevation angles are scanned at each observing cycle.

A super-blower is activated when the rain sensor detects rain. The super blower keeps the radome clear of rain or snow.

\subsubsection{Specifications}

Table 7. Instrument specifications.

\begin{tabular}{|l|l|}
\hline \multicolumn{1}{|c|}{ Parameter } & \multicolumn{1}{c|}{ Value } \\
\hline Data interface Primary computer port & RS422 $57600 \mathrm{~kb} / \mathrm{s} 8 \mathrm{~N} 1$ \\
\hline Data interface Auxiliary computer port & RS422 1.2-57600 kb/s 8N1 \\
\hline Power requirement (100 to 250 VAC / 50-60 Hz) & $\sim 200 \mathrm{~W}(400 \mathrm{~W}$ at cold start $)$ \\
\hline Weight & $27 \mathrm{~kg}$ \\
\hline Size & $50 \mathrm{X} 28 \mathrm{X} 76 \mathrm{~cm}$ \\
\hline Radiometric noise & $0.25 \mathrm{~K}(250 \mathrm{~ms}$ averaging time $)$ \\
\hline Long term stability & $<1 \mathrm{~K}$ over $1 \mathrm{yr}$ \\
\hline Measurement rate & $\sim 1 / 20 \mathrm{~s}$ \\
\hline Antenna beamwidth & $1.0^{\circ}$ \\
\hline Temperature range & $-50^{\circ}$ to $50^{\circ} \mathrm{C}$ \\
\hline Output & ASCII data files \\
\hline
\end{tabular}




\subsection{Theory of Operation}

The GVRP measures brightness temperatures at 15 channels between 170.0 and $183.31 \mathrm{GHz}$. The atmospheric emission in this spectral region is primarily due to water vapor, with some influence from liquid water. Channels in the wing of the absorption line are particularly sensitive to the presence of liquid water.

The sensitivity of the GVRP channels to the presence of water vapor is much stronger than that of the 22$\mathrm{GHz}$ water vapor line; however, the instrument response to the presence of PWV is nonlinear. The GVRP has one channel centered at the peak of the $183.31-\mathrm{GHz}$ line. This channel is sensitive to the presence of stratospheric water vapor when the humidity is very low.

\subsection{Calibration}

\subsubsection{Theory}

Each channel of the GVRP is calibrated at the factory by determining several parameters used in the calibration algorithm. Seven parameters are used in the calibration algorithm:

- Linearity correction exponent $(\alpha)$

- $1 /$ f noise suppression coefficient $(\mathrm{dTdG})$

- four temperature correction coefficients for the temperature dependence of the noise diode $(\mathrm{Ki}, \mathrm{i}=1$, 4)

- the effective noise diode temperature at $\mathrm{T}=290 \mathrm{~K}(\mathrm{Tnd} 290)$.

The noise diode requires periodic LN2 calibrations that are performed every three months. During LN2 calibrations, the two temperature references used to calibrate the noise diode are the black body and the Liquid Nitrogen.

Once the noise diode is calibrated, it can be used for frequent routine calibration. The black body is viewed every five minutes, and the noise diode is switched on and off while viewing the black body. The GVRP does not perform tip curves because its channels are too opaque.

\subsubsection{Procedures}

Brightness temperatures $T_{\text {sky }}$ are produced for each channel according to:

$$
T_{s k y}=\left(\frac{V_{s k y}}{\text { gain }_{s k y}}\right)^{1 / \alpha}-\operatorname{Trc} v_{s k y} .
$$

where $V_{s k y}$ is the signal recorded when the reflector is oriented towards the sky, gain sky $_{\text {is }}$ the gain during sky observations, and $\operatorname{Trc} v_{s k y}$ is the receiver temperature during sky observations. The gain during black body and sky observation is defined as: 


$$
\begin{aligned}
& \operatorname{gain}_{b b}=\left(\frac{V_{b b \_n d}^{1 / \alpha}-V_{b b}^{1 / \alpha}}{T n d 290+T c}\right)^{\alpha} \\
& \operatorname{gain}_{s k y}=\left(\frac{V_{s k y \_n d}^{1 / \alpha}-V_{s k y}^{1 / \alpha}}{T n d 290+T c}\right)^{\alpha} .
\end{aligned}
$$

The receiver temperature during black body and sky observations is:

$$
\begin{aligned}
& \operatorname{Trc}_{b b}=\left(\frac{V_{b b}}{\operatorname{gain}_{b b}}\right)^{1 / \alpha}-T k_{b b} \\
& \operatorname{Trc}_{s k y}=\operatorname{Trc}_{b b}+d \operatorname{Td} G\left(\operatorname{gain}_{s k y}-\operatorname{gain}_{b b}\right) .
\end{aligned}
$$

The temperature correction to the effective noise diode temperature is:

$$
T c=K 1+K 2 * T k_{b b}+K 3^{*} T k_{b b}^{2}+K 4 * T k_{b b}^{3} .
$$

Of the seven parameters used in the calibration algorithm, only the effective noise diode temperature is calibrated in the field. The remaining six parameters are determined at the factory.

\subsubsection{History}

- Deployed during RHUBC I in Barrow, Alaska February 1-March 30, 2007

- Deployed in Barrow, Alaska, April 1, 2008

- Moved to VOCALS campaign in the Southeast Pacific, September-December 2008

- Deployed during RHUBC II in Chile, August-October 2009

- Deployed in Barrow, Alaska, February 2010.

\subsection{Operation and Maintenance}

\subsubsection{User Manual}

Available by contacting the instrument mentor.

\subsubsection{Routine and Corrective Maintenance Documentation}

This information is not available for this instrument system.

\subsubsection{Software Documentation}

This information is not available for this instrument system. 


\subsubsection{Additional Documentation}

This section is not applicable to this instrument system.

\subsection{Glossary}

Uncertainty: We define uncertainty as the range of probable maximum deviation of a measured value from the true value within a $95 \%$ confidence interval. Given a bias (mean) error $B$ and uncorrelated random errors characterized by a variance $\sigma^{2}$, the root-mean-square error (RMSE) is defined as the vector sum of these,

$$
R M S E=\left(B^{2}+\sigma^{2}\right)^{1 / 2}
$$

( $B$ may be generalized to be the sum of the various contributors to the bias and $\sigma^{2}$ the sum of the variances of the contributors to the random errors). To determine the $95 \%$ confidence interval, we use the Student's $t$ distribution: $t_{\mathrm{n}, 0.025} \approx 2$, assuming the RMSE was computed for a reasonably large ensemble. Then the uncertainty is calculated as twice the RMSE.

\subsection{Acronyms}

See the ARM Acronyms and Abbreviations.

\subsection{Citable References}

[1] Radiometrics MP-183 User's Manual, REV. A. 


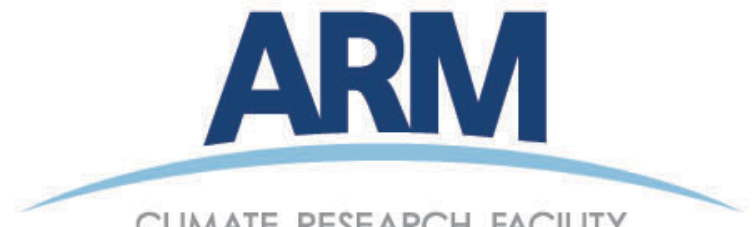

CLIMATE RESEARCH FACILITY

www.arm.gov

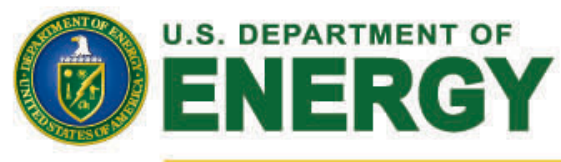

Office of Science 